\title{
Submembrane Assembly and Renewal of Rod Photoreceptor cGMP-Gated Channel: Insight into the Actin-Dependent Process of Outer Segment Morphogenesis
}

\author{
Ina Nemet, Guilian Tian, and ๑Yoshikazu Imanishi \\ Department of Pharmacology, School of Medicine, Case Western Reserve University, Cleveland, Ohio 44106-4965
}

\begin{abstract}
The photoreceptor outer segment (OS) is comprised of two compartments: plasma membrane (PM) and disk membranes. It is unknown how the PM renewal is coordinated with that of the disk membranes. Here we visualized the localization and trafficking process of rod cyclic nucleotide-gated channel $\alpha$-subunit (CNGA1), a PM component essential for phototransduction. The localization was visualized by fusing CNGA1 to a fluorescent protein Dendra2 and expressing in Xenopus laevis rod photoreceptors. Dendra2 allowed us to label CNGA1 in a spatiotemporal manner and therefore discriminate between old and newly trafficked CNGA1-Dendra2 in the OS PM. Newly synthesized CNGA1 was preferentially trafficked to the basal region of the lateral OS PM where newly formed and matured disks are also added. Unique trafficking pattern and diffusion barrier excluded CNGA1 from the PM domains, which are the proposed site of disk membrane maturation. Such distinct compartmentalization allows the confinement of cyclic nucleotide-gated channel in the PM, while preventing the disk membrane incorporation. Cytochalasin D and latrunculin A treatments, which are known to disrupt F-actin-dependent disk membrane morphogenesis, prevented the entrance of newly synthesized CNGA1 to the OS PM, but did not prevent the entrance of rhodopsin and peripherin/rds to the membrane evaginations believed to be disk membrane precursors. Uptake of rhodopsin and peripherin/rds coincided with the overgrowth of the evaginations at the base of the OS. Thus F-actin is essential for the trafficking of CNGA1 to the ciliary PM, and coordinates the formations of disk membrane rim region and OS PM.
\end{abstract}

Key words: CNGA1; cyclic nucleotide-gated channel; morphogenesis; photoreceptor; retina; rhodopsin

\section{Introduction}

Sensory neurons orchestrate membrane morphogenic events that restrict sensory proteins and associated downstream signaling components to specific subcellular locations. The sensory portion of rod photoreceptor, outer segment (OS), requires two separate membrane compartments, disk membrane and OS plasma membrane (PM). Phototransduction is initiated when rhodopsins in the disk membranes absorb photons. Rhodopsin activation ultimately leads to hydrolysis of cGMP. Changes in [cGMP] are sensed by the cGMP-gated (CNG) channel located on the PM (Cook et al., 1989). The CNG channel is thus essential

\footnotetext{
Received March 30, 2014; revised May 1, 2014; accepted May 6, 2014.

Author contributions: I.N. and Y.I. designed research; I.N. performed research; G.T. contributed unpublished reagents/analytic tools; I.N. and Y.I. analyzed data; I.N. and Y.I. wrote the paper.

This work was supported by the U.S. National Institutes of Health grants EY020826 and EY011373. We thank Richard Lee for excellent technical assistance in the preparation of this paper. We also thank Dr. John Mieyal, Dr. Johannes von Lintig, and Philip Ropelewski (Case Western Reserve University, Cleveland, $\mathrm{OH}$ ) for critically reading this manuscript before submission and for their helpful suggestions. We thank Dr. William N. Zagotta from University of Washington for full-length bCNGA1 CDNA and Dr. Hisashi Fujioka, the director of the Electron Microscopy Core Facility at Case Western Reserve University, for his support on electron microscopy. We also thank Dr. Rajesh Ramachandran and Dr. Patrick Macdonald (Case Western Reserve University) for helpful discussion about protein diffusion and Dr. Mariana Rosca (Case Western Reserve University) for providing neutral protease and giving helpful instructions for the treatment.

The authors declare no competing financial interests.

Correspondence should be addressed to Yoshikazu Imanishi, Department of Pharmacology, School of Medicine, Case Western Reserve University, Cleveland OH 44106-4965. E-mail: yxi19@case.edu.

DOI:10.1523/JNEUROSCI.1282-14.2014

Copyright $\odot 2014$ the authors $\quad 0270-6474 / 14 / 348164-11 \$ 15.00 / 0$
}

for vertebrate phototransduction and consists of one $\beta$ - and three $\alpha$-subunits (Weitz et al., 2002; Zheng et al., 2002; Zhong et al., 2002). While $\alpha$-subunits can form a functional channel by themselves (Kaupp et al., 1989), $\beta$-subunits cannot (Chen et al., 1993). The PM location of the CNG channel appears to be required for proper coordination of the disk membrane and PM compartments, as evidenced by aberrant OS structures in the CNG $\beta$-subunit gene-deficient mouse (Zhang et al., 2009; Gilliam et al., 2012). Disk membranes are formed at the bottom portion of the OS PM (Young, 1967). By yet uncharacterized mechanisms, CNG channel is prevented from entering the disk membranes, and maintains its localization exclusively to the OS PM (Cook et al., 1989). Specific sorting of CNG channel should be coordinated with membrane morphogenesis events that then accomplish the observed functional specification of PM and disk membranes (Molday and Molday, 1987).

The cellular mechanisms of OS renewal are vital for photoreceptors, and malfunctions of the mechanisms lead to retinal dystrophies (Wright et al., 2010). While the process of disk membrane renewal was previously visualized (Young, 1967), it is currently unclear how the OS PM, which contains CNG channel, is renewed. Regarding the process of OS morphogenesis, two hypotheses have been proposed. One hypothesis is the "endosome model" in which the disk membranes are formed by multiple endosomes fusing to grow into larger disks (Miyaguchi and Hashimoto, 1992; Obata and Usukura, 1992; Chuang et al., 2007; 


\section{Hypothesis 1}
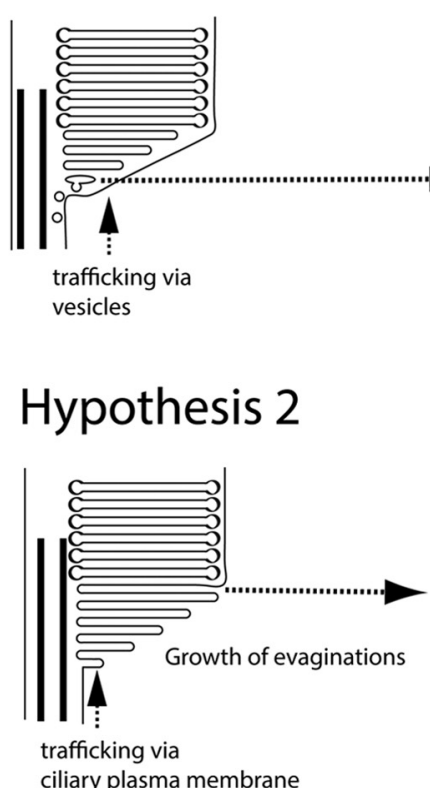

ciliary plasma membrane

\begin{abstract}
Process of disk rim and disk formation
\end{abstract}

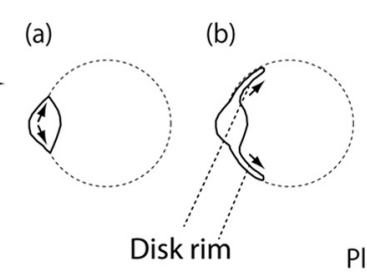

(c)

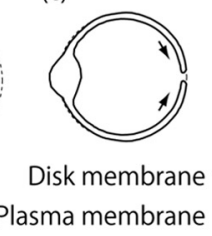

Figure 1. Models for disk membrane morphogenesis. Hypothesis 1: In the endosome model, disk membranes are formed by multiple endosomes fusing to grow into larger disks (Miyaguchi and Hashimoto, 1992; Obata and Usukura, 1992; Chuang et al., 2007). It is unclear when and how the disk rim is formed and if immature disks have rim regions. PM and disk membrane renewal are not necessarily synchronized. Hypothesis 2: In the evagination model, disk membranes are formed by initial PM evagination, which then becomes sealed to generate closed and mature disks (Steinberg et al., 1980). The sealing also results in the generation of the disk rim and the new PM domain.

Fig. 1, Hypothesis 1). Another hypothesis is the "evagination model." In this model, the disk membrane is generated by initial PM evagination, which then becomes sealed to generate closed and mature disks (Steinberg et al., 1980; Fig. 1, Hypothesis 2). While the endosome hypothesis does not explain the process of OS PM morphogenesis, the evagination hypothesis is consistent with disk membrane and PM compartments generated simultaneously. In testing the hypotheses, one of the major obstacles has been the lack of techniques to monitor the renewal process of PM-specific components.

In this manuscript we studied the process of CNG channel incorporation into the OS in transgenic Xenopus laevis rod photoreceptors. By using specific genetic labeling of CNGA1 with photoconvertible protein Dendra2 (Dend2; Gurskaya et al., 2006; Chudakov et al., 2007), the mobility of CNGA1 along the PM was tested. Then the process of renewing CNGA1 was visualized in conjunction with the process of renewing disk membrane components. Through these experiments, we were able to refine the model for the overall process of OS renewal.

\section{Materials and Methods}

Constructs. Full-length bovine cyclic nucleotide-gated channel $\alpha-1$ (bCNGA1) cDNA was a generous gift from Dr. William N. Zagotta (Department of Physiology and Biophysics, University of Washington, Seattle, WA). The coding region of bCNGA1 was cloned into a TOPO vector, which contained the Xenopus rhodopsin promoter upstream and Dend2 (Clontech Laboratories) downstream of the cloning site by using standard methods combining PCR, DNA recombination, and QuikChange techniques. Sequences of the DNA expression vectors were confirmed. Human rhodopsin was fused to Dend2 and 1D4 epitope (rhodopsinDend2-1D4), and $X$. laevis peripherin/rds was fused to Dend2 (peripherin/rds-Dend2) as described previously (Lodowski et al., 2013; Tian et al., 2014). (d)

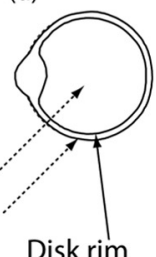

Generation of transgenic X. laevis. All animal experiments were performed in accordance with the Association for Research in Vision and Ophthalmology Statement for the Use of Animals in Ophthalmic and Vision Research, and based on the protocol approved by the Institutional Animal Care and Use Committee at Case Western Reserve University. Transgenic X. laevis expressing bCNGA1-Dend2, rhodopsinDend2-1D4, and peripherin/rds-Dend2 was generated using the intracytoplasmic sperm injection method (Sparrow et al., 2000). Injected eggs were housed at $16^{\circ} \mathrm{C}$. Tadpoles of either sex were screened through visual inspection of green fluorescence in their eyes when they were $7 \mathrm{~d}$ old and divided into three categories, "light," "medium," and "bright," according to the intensity of green fluorescence in their eyes. In all experiments, tadpoles were medium or bright and 12-16 d old (stage range 46-47; Nieuwkoop and Faber, 1967). Occasionally, overexpression of bCNGA1-Dend 2 caused distortion of the cell shape, likely due to toxicity of aberrantly high levels of bCNGA1Dend2. Therefore, the cells that overexpressed bCNGA1-Dend2 were not included in the analysis. Unless otherwise specified, a minimum of four animals was used in each experiment. Albino X. laevis was used for all the procedures.

Immunofluorescence microscopy. Fixed eye tissues were prepared as previously described (Lodowski et al., 2013; Tian et al., 2014). Briefly, tadpoles were anesthetized, decapitated, and their heads fixed in $4 \%$ formaldehyde in PBS for $6 \mathrm{~h}$ at room temperature. The fixed heads were then incubated in $5,10,15$, and $20 \%$ sucrose in phosphate buffer for $30 \mathrm{~min}$ each. The heads were then placed in a mixture of O.C.T. Compound (Tissue-Tek; Sakura Finetek) and 20\% sucrose (1:2, v/v) solution overnight at $4^{\circ} \mathrm{C}$. Frozen heads were sectioned on a cryostat (CM1850; Leica) at $-20^{\circ} \mathrm{C}$ into $12-\mu \mathrm{m}$-thick slices. For retinal flat mounts, the neural retina was excised from each eye in modified Wolf medium (55\% MEM; Invitrogen; $31 \%$ Earle's sodium-free BBS, 10\% FBS, $30 \mathrm{~mm} \mathrm{NaHCO}_{3}$, and $700 \mathrm{mg} / \mathrm{L}$ D-glucose). Neural retinas were fixed in $4 \%$ formaldehyde in PBS for $1 \mathrm{~h}$ at room temperature or methanol/DMSO $(80: 20 ; \mathrm{v} / \mathrm{v})$ for $15 \mathrm{~min}$ at $-20^{\circ} \mathrm{C}$ and processed for immunofluorescence. Fixed eye sections or retinas were blocked in $1.5 \%$ normal goat serum diluted in PBS with $0.1 \%(\mathrm{v} / \mathrm{v})$ Triton X-100 for $1 \mathrm{~h}$, incubated with primary antibody overnight, and then secondary antibody for $1 \mathrm{~h}$ at room temperature. For visualizing axoneme, bCNGA1-Dend2, and endogenous CNGA1, mouse anti-acetylated tubulin (Sigma-Aldrich; catalog \#T6793, RRID: AB_477585), rabbit anti-Dendra2 serum (Lodowski et al., 2013), and mouse anti-Carassius auratus-CNGA1 (Abcam; catalog \#ab105878, RRID: AB_10866456) were used as primary antibodies. Goat anti-mouse Cy3 (Jackson ImmunoResearch; catalog \#115-166-003), donkey anti-rabbit Alexa Fluor 488 (Jackson ImmunoResearch; catalog \#711-545-152), and donkey anti-mouse Alexa Fluor 488 (Jackson ImmunoResearch; catalog \#711-545-152) were used as secondary antibodies. For visualizing F-actin, Alexa Fluor 546-conjugated phalloidin (Invitrogen), at a concentration of 22 $\mathrm{nM}$, was incubated with retinas overnight at room temperature in PBS with $0.1 \%(\mathrm{v} / \mathrm{v})$ Triton X-100.

Disruption of calyceal process-OS links by treatment with dispase and BAPTA. Xenopus eyes were dissected in serum-free modified Wolf medium and retinas were separated from retinal pigment epithelium and incubated on ice in Wolf medium containing $100 \mu \mathrm{g} / \mathrm{ml}$ dispase (neutral protease; Worthington) for $5 \mathrm{~min}$, followed by Wolf medium containing $5 \mathrm{~mm}$ BAPTA (Life Technologies) for an additional $5 \mathrm{~min}$. The retinas were fixed and processed for confocal microscopy as described above. 

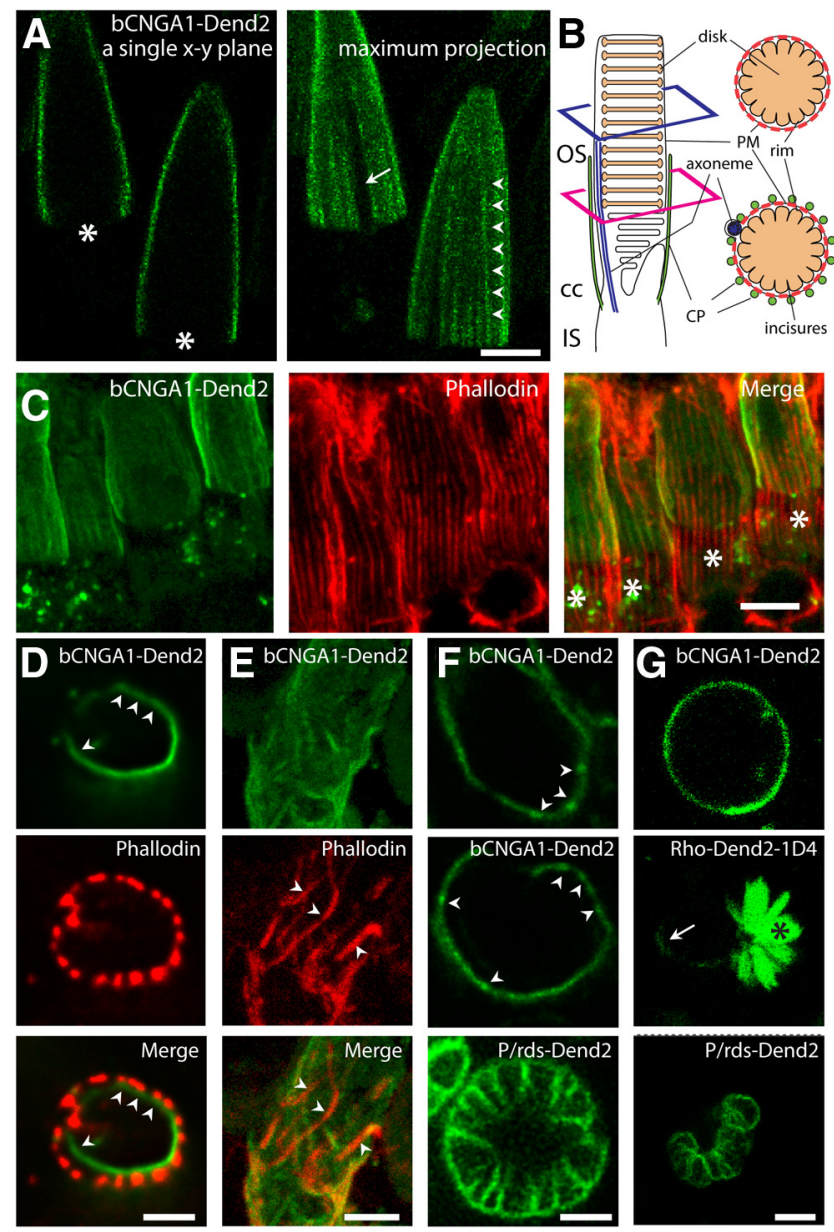

Figure 2. $\quad b C N G A 1-D e n d 2$ localizes to the PM of the rod OS. $\boldsymbol{A}$, The localization of bCNGA1Dend2 in X. laevis rods. $\boldsymbol{B}$, Xenopus rod photoreceptor cell: the connecting cilium (CC) connects the IS and OS. Disks are located in the OS, and surrounded by the PM; CNGA1 localization is denoted by the dashed red lines. $\boldsymbol{C}-\boldsymbol{E}$, Phalloidin-stained bCNGA1-Dend 2 transgenic Xenopus retina indicates the CPs are enriched with F-actin filaments (red). CPs do not contain bCNGA1Dend2 (green). $\boldsymbol{E}$, Retinas from bCNGA1-Dend2 transgenic tadpoles were pretreated with neutral protease dispase and BAPTA to partially destroy $(P-O S$ connections (arrowheads). $\boldsymbol{F}$, The localization of bCNGA1-Dend2 (top and middle) in PM and peripherin/rds-Dend2 (P/rds-Dend2, bottom) in disk rims and incisures of $X$. laevis rods. The middle represents the region transecting axoneme, around which bCNGA1-Dend2 is absent. G, Localization of bCNGA1-Dend2 in PM (top), rhodopsin-Dend2-1D4 (Rho-Dend2-1D4) in PM (arrow) and disks (asterisk; middle), and peripherin/rds-Dend2 (P/rds-Dend2) in disk rims (bottom) in hypotonically lysed retinas. Images are maximum projections of optical slices $(\boldsymbol{A}$, right, $\boldsymbol{C}, \boldsymbol{E})$ or single confocal images $(\boldsymbol{A}$, left, $\boldsymbol{D}, \boldsymbol{F}, \boldsymbol{G})$. Images are either from live and unfixed retina $(\boldsymbol{A})$; fixed retina $(\boldsymbol{C}-\boldsymbol{F})$; or hypotonically lysed, unfixed retina $(\boldsymbol{G})$. Images $(\boldsymbol{D})$ and $(\boldsymbol{F})$ were processed by $2 \mathrm{D}$ blind deconvolution, to deblur the images and to reveal bCNGA1-Dend2-enriched structures (arrowheads). Animals were $14 \mathrm{~d}$ old. Scale bars: $\boldsymbol{A}, \boldsymbol{C}, \boldsymbol{E}, \boldsymbol{G}, 5 \mu \mathrm{m} ; \boldsymbol{D}, \boldsymbol{F}, 2 \mu \mathrm{m}$.

Photoconversion of Dend2 fused to bCNGA1, rhodopsin, and peripherin/ rds; and tissue preparation for imaging. Dend2 was photoconverted as previously described (Lodowski et al., 2013). Briefly: X. laevis transgenic tadpoles (12-14 d old, stage range of 46-47) were anesthetized and laid in $6 \%$ methyl cellulose (Sigma-Aldrich). Photoconversion was performed by directing a $405 \mathrm{~nm}$ light source at their heads for 15-20 min with periodic breaks. For confocal imaging, tadpoles were killed $48 \mathrm{~h}$ after photoconversion.

Confocal microscopy. Living retinas, fixed retinal sections, retinal flat mounts, or hypotonically treated retinas were imaged using the HCX PL APO CS $40.0 \times 1.25$ oil UV objective of a Leica TCS SP2 laser scanning confocal microscope. Argon (488 nm) and helium/neon (543 nm) lasers were used for excitation. Images were acquired using Leica Confocal Software version 2.61. Leica Lite software was used to construct maxi-
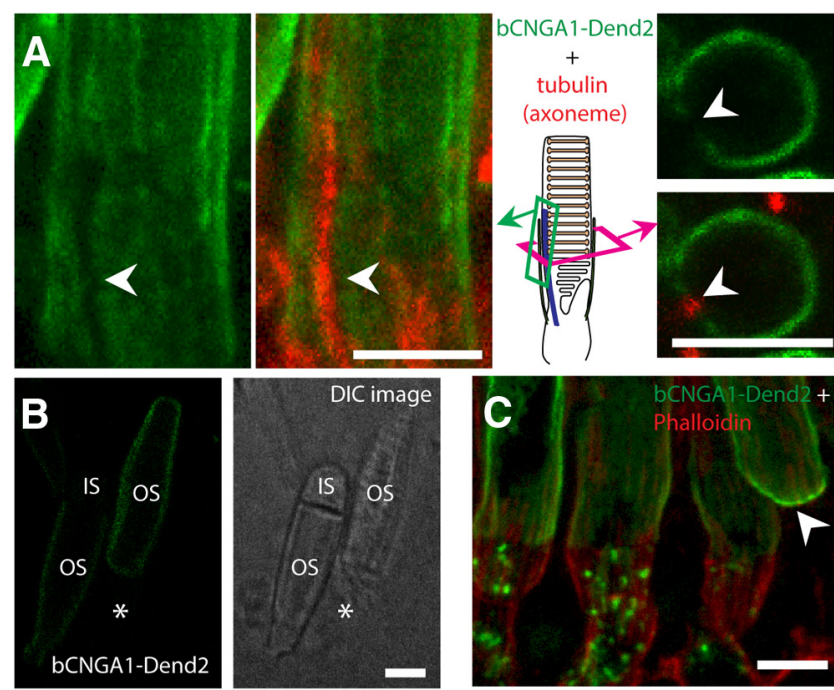

Figure 3. $\quad b C N G A 1-D e n d 2$ is excluded from the PM domains proximal to the axoneme and at the bottom of OS. $\boldsymbol{A}, \mathrm{bCNGA1-Dend2}$ does not localize in the proximity of the axoneme (arrowheads); bCNGA1-Dend2 (green) was colabeled with anti-acetylated tubulin (red). B, C, The localization of bCNGA1 in the rod cells with and without IS, respectively. bCNGA1-Dend2 localization forms an aberrant closed shape ( $\boldsymbol{B}$, left, asterisk) only in the OS detached from the IS as revealed by DIC image ( $\boldsymbol{B}$, right, asterisk). In $\boldsymbol{C}$, F-actin was labeled with fluorescent phalloidin (red) to reveal IS structures, which are not attached to $0 S$ with aberrant localization of bCNGA1Dend2 (arrowhead). Images are either from fixed retina $(\boldsymbol{A}, \boldsymbol{C})$ or live and unfixed retina $(\boldsymbol{B})$. Animals were $14 \mathrm{~d}$ old. Scale bars: $5 \mu \mathrm{m}$.
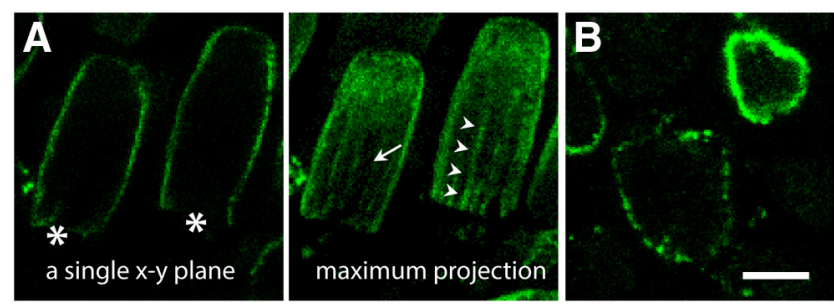

Figure 4. OS PM localization of endogenous X. laevis CNGA1. The localization of endogenous $X$. laevis CNGA1 in intact OSPM $(\boldsymbol{A})$ and hypotonically lysed OS PM $(\boldsymbol{B})$. Images are obtained from methanol/DMSO-fixed retina $(\boldsymbol{A})$ or hypotonically lysed and $4 \%$ formaldehyde-fixed retina $(\boldsymbol{B})$. Animals were $14 \mathrm{~d}$ old. Scale bar, $5 \mu \mathrm{m}$.

mum projection images from $z$-stacks. Live retinas were imaged in a modified Wolf medium (see above) inside a sealed chamber (DMIRB/E ONICS-D35; Tokai Hit) that maintained temperature $\left(21^{\circ} \mathrm{C}\right)$ and gas concentration $\left(95 \% \mathrm{O}_{2}\right.$ and $\left.5 \% \mathrm{CO}_{2}\right)$ on the microscope during the imaging. OS PM was ruptured by exposing retinas for $5 \mathrm{~min}$ to a hypotonic buffer ( 2 mM HEPES and 2 mM EGTA, pH 7.4). Rupturing enabled spatial separation of disk membranes from the OS PM for microscopy observation.

Images analysis. Contrast of red fluorescence for rhodopsin-Dend21D4 and peripherin/rds-Dend2 was enhanced by histogram-stretching method using the Adobe Photoshop CS6 (Adobe Systems) to discern the absence and presence of red fluorescent Dend2 fusion proteins in overgrown evaginations. Exactly the same enhancement was applied to all images. For quantitative analysis, intensity profiles were determined using original images before any intensity adjustments. Intensity profiles for green and red rhodopsin-Dend2-1D4 and peripherin/rds-Dend2 were determined in a single optical section by using ImageJ software (RRID: nif-0000-30467). Some $x-y$ images of the OS cross sections were processed by 2D blind deconvolution using AutoDeblur and AutoVisualize 9.3 (MediaCybernetics).

Eye culture. Immediately after photoconversion, transgenic animals were placed in $0.026 \%$ tricaine methanesulfonate for 2-3 min followed by decapitation and removal of eyes into modified Wolf medium under 

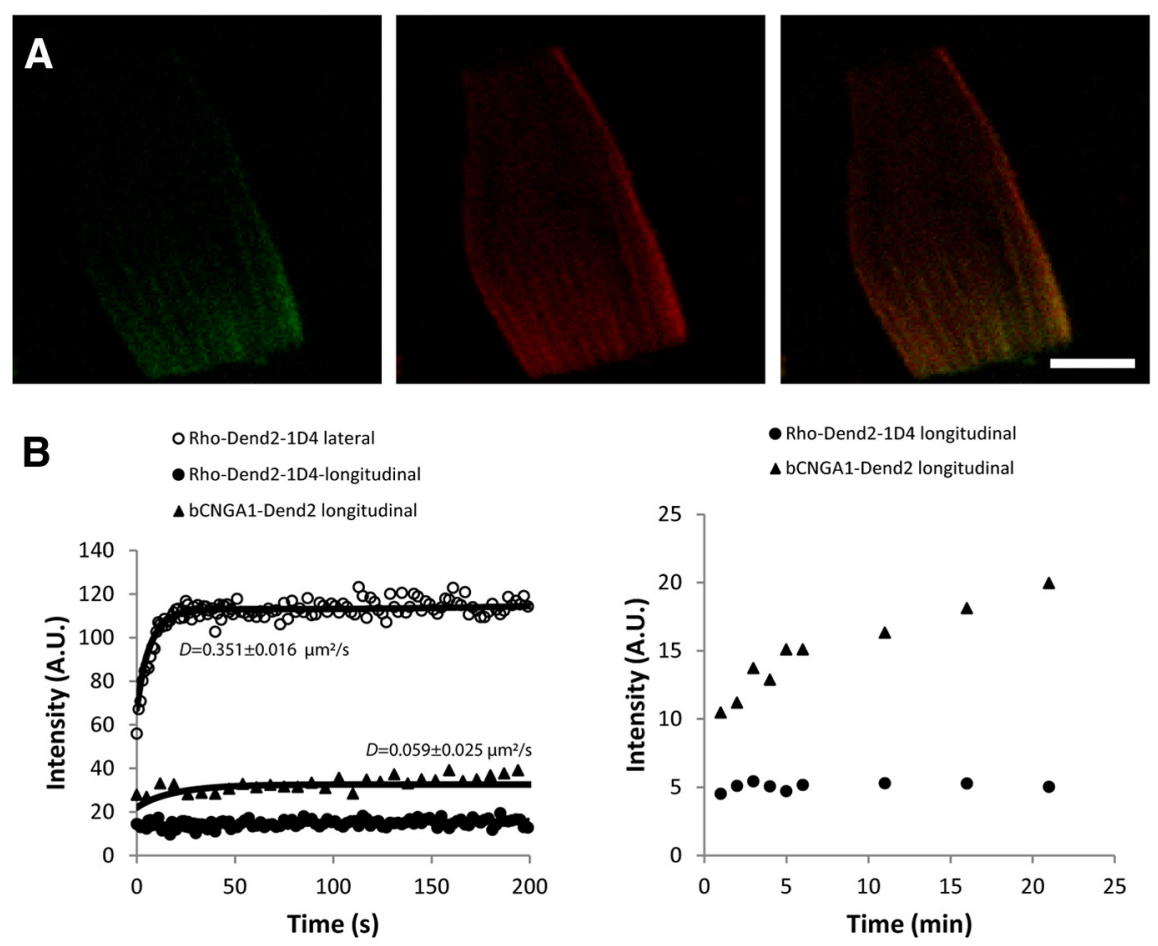

Figure 5. bCNGA1-Dend2 mobility in the PM of the rod OS. $A$, The photoconversion technique allows discrimination of old (red) from newly synthesized (green) bCNGA1-Dend2. Forty-eight hours after photoconversion, newly added bCNGA1-Dend2 was concentrated at the basal portion of the rod $0 S$ where newly formed disk membranes are added (Lodowski et al., 2013). Images are from live and unfixed retina. Scale bar, $5 \mu \mathrm{m}$. $\boldsymbol{B}$, Lateral and longitudinal diffusion of rhodopsin-Dend2-1D4 and longitudinal diffusion of bCNGA1-Dend2 were studied by FRAP in X. laevis rods. FRAP measurements were corrected and fitted to curves to estimate the diffusion coefficients $(D)$ and percentage of immobile fraction as described in Materials and Methods. A.U., arbitrary units.

an atmosphere of $95 \% \mathrm{O}_{2}$ and $5 \% \mathrm{CO}_{2}$. The eyes were incubated in the presence of cytochalasin D (25 $\mu \mathrm{M}$ in DMSO) or latrunculin A (500 nM in DMSO). After $24 \mathrm{~h}$ or $48 \mathrm{~h}$ of incubation, retinas were used for imaging experiments. DMSO was added to the untreated eyes $(0.25 \% \mathrm{v} / \mathrm{v}$ of DMSO final concentration).

Fluorescence recovery after photobleaching measurements. Vertical mobility of bCNGA1-Dend2 and vertical and lateral mobility of rhodopsinDend2-1D4 were assessed by measuring fluorescence recovery after photobleaching (FRAP) in living Xenopus rods. FRAP was measured by a Leica TCS SP2 laser scanning confocal microscope (Leica Microsystems) using the FRAP module in the Leica Confocal Software version 2.61 Build 1537 following the procedure previously described (Wang et al., 2008).

Electron microscopy. Transmission electron microscopy was performed as described previously (Imanishi et al., 2008). Briefly, tadpole eyeballs were fixed with triple aldehyde/DMSO fixative for $2 \mathrm{~h}$ at room temperature, rinsed with phosphate buffer ( $1 \mathrm{~mm}, \mathrm{pH} 7.4)$, and then postfixed for $2 \mathrm{~h}$ in a 1:1 mixture of osmium tetroxide $(2 \%)$ and potassium ferricyanide $(3 \%)$. The specimens were rinsed with distilled water followed by soaking overnight in an acidified solution of uranyl acetate $(0.25 \%)$. Then the specimens were dehydrated with increasing concentrations of ethanol, passed through propylene oxide, and embedded in an Epon mixture. Thin sections $(\sim 80 \mathrm{~nm})$ were sequentially stained with acidified methanolic uranyl acetate and lead tartrate, and examined with a JEOL 1200EX electron microscope. Three animals were used for the analysis.

\section{Results}

\section{Submembrane localization of CNGA1 in rod OS PM}

To obtain insight into the process of CNGA1 trafficking, bCNGA1 was fused to Dend2 fluorescent protein (bCNGA1Dend2) and expressed in X. laevis rod photoreceptor cells. Fluorescence localization of bCNGA1-Dend2 was consistent with its
PM localization (Cook et al., 1989) in the OS (Fig. 2A). 2D confocal sections revealed the localization of bCNGA1Dend2 in the edge of OS, forming archlike shapes (Fig. $2 A$, left, a single $x-y$ plane), which are indicative of OS PM localization. 3D projection images revealed the detailed sub-PM localization of bCNGA1-Dend2 (Fig. 2A, right, maximum projection of multiple confocal sections in the same area). bCNGA1-Dend2 was localized in the OS PM and was concentrated within vertically oriented features (Fig. 2A, right, arrowheads).

Within the rod OS, similarly vertically oriented features were previously observed for calyceal processes (CPs) and disk incisures, which are perpendicularly aligned through the OS (Tam et al., 2004; Sahly et al., 2012; Fig. 2B). However, we found that bCNGA1-Dend2 is not localized either in CPs or in incisures, but localized in the OS PM. The lack of bCNGA1-Dend2 in phalloidin-positive CPs was evident from the lack of bCNGA1-Dend2 in the inner segment (IS) layer where CPs originate (Fig. 2C, asterisks) and the absence of their colocalization in the cross section of the OS (Fig. $2 D$ ). To further clarify the localization of bCNGA1-Dend2, we partially dissociated the CPs from the OS PM by neutral protease dispase and BAPTA (Fig. 2E). The vertically oriented features did not coincide with the portions of the CPs that were successfully dissociated from the OS (Fig. 2E, arrowheads). Thus this experiment further confirmed the localization of bCNGA1-Dend2 in the OS PM. The lack of bCNGA1-Dend2 in incisures was evident from the comparison of peripherin/rds-Dend2 and bCNGA1-Dend2 localizations. While peripherin/rds-Dend2 localized to incisures inside the disk membranes (Fig. 2F, bottom), bCNGA1-Dend2 was observed in the location encircling the OS (Fig. 2F, top and middle) with regions enriched with bCNGA1-Dend2 (Fig. 2D, F, arrowheads), consistent with the location being the PM but not the incisures (Fig. $2 F$ ). Thus CNGA1 is concentrated in the vertical striped features of OS PM, but not localized to the incisures or CPs.

Previously, hypotonically treated OS demonstrated rapid rupturing and whirling of OS PM, which was then effectively separated from the disk membranes (Roof and Heuser, 1982; Molday and Molday, 1987). Consistently, in hypotonically treated OS membranes, bCNGA1-Dend2 localized in circles-a pattern characteristic for PM proteins (Fig. 2G, top). Rhodopsin-Dend2-1D4 localized in the rod OS disks (Fig. 2G, middle, asterisk) and PM (Fig. $2 G$, middle, arrow). Peripherin/rds-Dend2 localized to disk rims with a pattern consistent with that of ruptured OS (Fig. 2G, bottom).

While localized to the majority of OS PM regions, bCNGADend2 was conspicuously absent from two subdomains of the OS PM, namely the bottom of the OS (Fig. $2 A$, a single $x-y$ plane, asterisks) and the region proximal to the axoneme (Figs. $2 A$, right, arrow; $3 A$, arrowheads). In $<1 \%$ of rods in fixed eye tissues, we observed the bottom of the OS being closed. However, this 
bottom localization of bCNGA1-Dend2 was only observed when the rod OS was detached from the IS (Fig. 3B, asterisk; $C$, arrowhead). Thus proper localization of CNGA1 requires intact connection between OS and IS, and hence healthy states of the rod photoreceptors.

These observations were derived from bCNGA1-Dend2 transgenically introduced to Xenopus rods. Previously, localization studies of endogenous CNGA1 have been limited to species such as mouse and bovine, which harbor very thin OSs. Submembrane assembly of endogenous CNG channel has not been addressed likely due to difficulties in resolving submembrane architectures in these thin OSs. By taking advantage of the large OS architecture of Xenopus rods, we tested localization of endogenous CNG channel using mouse anti-C. auratusCNGA1 antibody that also recognized $X$. laevis rod CNGA1. Anti-CNGA1 recognized the OS PM (Fig. 4). The detailed localization pattern of endogenous Xenopus CNGA1 was identical to that of bCNGA1-Dend2 (compare Figs. 2, 4). Endogenous Xenopus CNGA1 forms arch-like shapes in $2 \mathrm{D}$ confocal sections (Fig. 4A, left), and thus is excluded from the PM at the bottom of the OS (Fig. $4 A$, left, asterisks) where disk membrane morphogenesis is considered to occur. Xenopus CNGA1 was concentrated within multiple vertically oriented features (Fig. $4 A$, right, arrowheads); however, it was absent from a single vertical feature being consistent with the area proximal to an axoneme (Fig. $4 A$, right, arrow). In hypotonically treated OS membranes, endogenous CNGA1 localized in circles (Fig. $4 B$ )-the same pattern as in hypotonically treated bCNGA1-Dend2 transgenic OS membranes (compare Figs. $2 G$, top, $4 B$ ) Thus, endogenous Xenopus CNGA1 localizes accurately to the OS PM, and specifically compartmentalized to sub-PM domains in a pattern identical to bCNGA1-Dend 2 transgenically introduced to Xenopus rods.

\section{Renewal and mobility of CNGA1 in the OS PM}

The rod photoreceptor OS consists of disk membranes and PM, both of which are actively renewed. While the process of disk membrane renewal is well established, it has been unclear how the PM proteins are renewed in the OS. Based on past studies using autoradiography (Young, 1967) and more recently photoconversion techniques (Lodowski et al., 2013; Tian et al., 2014), disk membrane components, rhodopsin and peripherin/rds, are added at the base of the OS. To obtain insights into the process of renewing OS PM components, we used the photoconversion technique (Lodowski et al., 2013) to distinguish between newly synthesized bCNGA1-Dend2 in green and pre-existing photoconverted bCNGA1-Dend 2 in red. CNGA1 was tracked since it is an integral component of the OS PM (Fig. 2; Cook et al., 1989), and appears essential for the coordination of the disk and PM
B
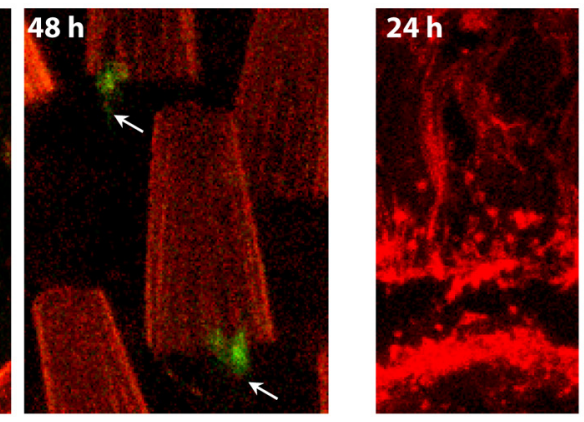

F-actin

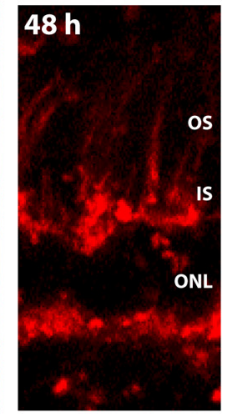

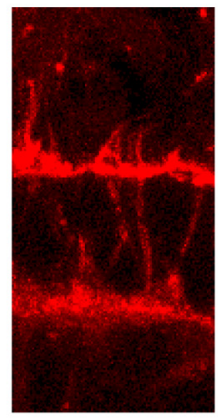
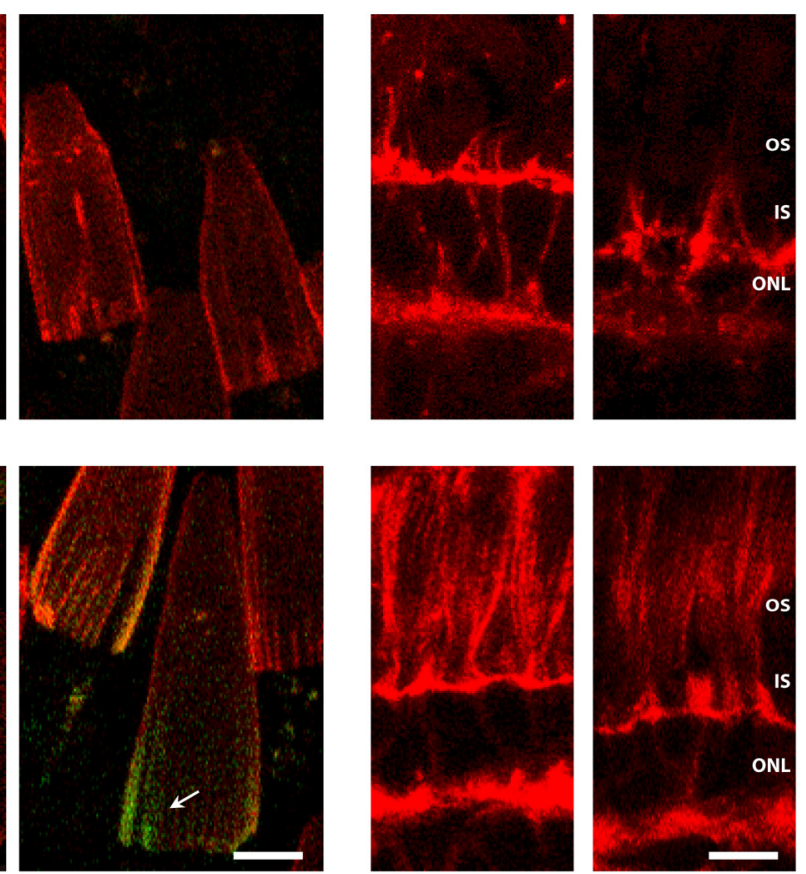

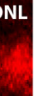

Figure 6. Entrance of bCNGA1-Dend2 to the rod OS PM is F-actin dependent. $A$, Localization of old (red) and newly synthesized (green, arrows) bCNGA1-Dend2 after cytochalasin D, latrunculin A, or DMSO (vehicle control) treatment for 24 and 48 h. $\boldsymbol{B}$ Cytochalasin D and latrunculin A disrupt F-actin filaments. Animals were $14 \mathrm{~d}$ old at the time of photoconversion. Images are either from live and unfixed retina $(\boldsymbol{A})$ or fixed retina $(\boldsymbol{B})$. ONL, outer nuclear layer. Scale bars: $5 \mu \mathrm{m}$.

structures (Poetsch et al., 2001; Zhang et al., 2009). Newly synthesized bCNGA1-Dend2 was concentrated at the basal portion of the lateral OS PM $48 \mathrm{~h}$ after photoconversion (Fig. 5A). Previous studies have indicated that new disk membranes are added to the basal OS (Young, 1967; Besharse et al., 1977). Thus our observations suggest that new CNGA1 is added to the OS proximal to where newly formed disk membranes are added.

The accumulation of new bCNGA1-Dend2 at the basal OS indicates that CNGA1 channels are rather immobile. Otherwise, new bCNGA1-Dend2 must have diffused throughout the length of the OS. To confirm that this immobility is not due to Dend2, which was fused to CNGA1, we compared the mobility of bCNGA1-Dend2 to that of rhodopsin fused to Dend2. To understand the mobility of CNGA1 on the PM, the vertical mobility of CNG channel was determined by measuring FRAP (Fig. 5B). bCNGA1-Dend 2 diffusion along the axis was restricted as demonstrated by a small diffusion coefficient $(D)$ value of $0.059 \pm$ $0.025 \mu \mathrm{m}^{2} / \mathrm{s}$ ( $n=16$ cells from 4 tadpoles). In control experiments, lateral diffusion of human rhodopsin fused to Dend2 (rhodopsin-Dend2-1D4; Lodowski et al., 2013) was measured. Calculated $D$ for lateral diffusion of rhodopsin-Dend2-1D4, after 

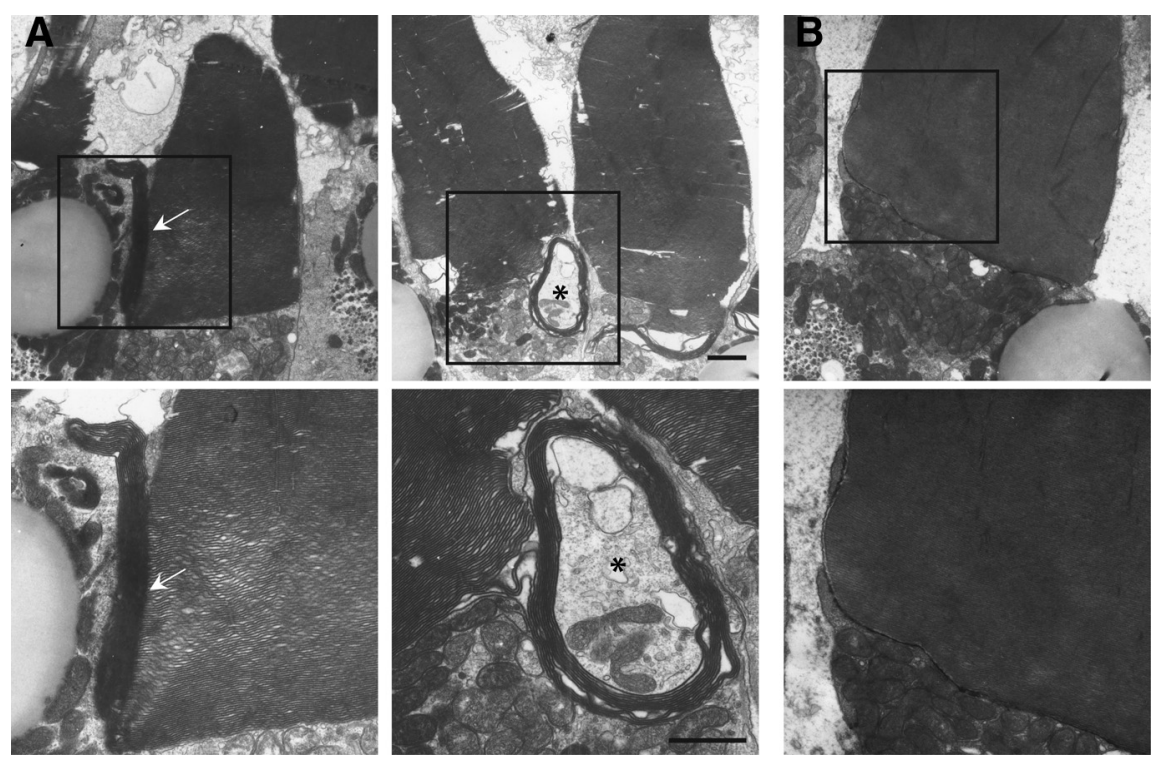

Entrance of CNGA1 to the rod OS PM is F-actin dependent

F-actin is known to bridge the ciliary microtubule and the PM (Arikawa and Williams, 1989), and may mediate protein trafficking. To test the potential involvement of F-actin on bCNGA1-Dend2 trafficking to the rod OS PM, tadpole eyes expressing bCNGA1-Dend2 were cultured and incubated with $25 \mu \mathrm{M}$ cytochalasin $\mathrm{D}$, a reagent that disrupts $\mathrm{F}$-actin (Fig. 6A, top). In this experiment, bCNGA1-Dend2 was photoconverted to red right before cytochalasin $\mathrm{D}$ treatment, and trafficking of new bCNGA1-Dend2 (green) was monitored at 24 and $48 \mathrm{~h}$ after photoconversion. After cytochalasin D treatment, new bCNGA1-Dend2 failed to enter the OS PM (Fig. 6A, top), and aggregated at the base of the OS (Fig. $6 A$, top right, arrows). In the absence of cytochalasin D treatment, bCNGA1-Dend2 entered the $\mathrm{OS}$ in cultured tadpole eyes (Fig. 6A, bottom, arrows; as observed for in vivo experiments). Cytochalasin D-dependent disruption of F-actin was

corrections for the underestimation caused by incisures (Najafi et al., 2012), was $0.351 \pm 0.016 \mu \mathrm{m}^{2} / \mathrm{s}$ ( $n=12$ cells from 4 tadpoles). This $D$ value is significantly larger than that for bCNGA1Dend 2 ( $p<0.001$ by $t$ test) and it is in good agreement with the values for diffusion coefficients obtained for native rhodopsin $\left(D=0.2-0.6 \mu \mathrm{m}^{2} / \mathrm{s}\right.$; Liebman and Entine, 1974; Wey et al., 1981; Gupta and Williams, 1990) and rhodopsin-EGFP (0.28-0.4 $\mu \mathrm{m}^{2} / \mathrm{s}$ ) in disk membranes (Wang et al., 2008; Muradov et al., 2009). As rhodopsin-Dend2-1D4 can diffuse rather rapidly, limited diffusion of bCNGA1-Dend2 is not due to Dend2, but rather the property of CNGA1.

Despite the diffusion being limited for bCNGA1-Dend2, there is a mobile fraction of bCNGA1-Dend2. In the FRAP experiment, on average $32 \%$ ( $n=16$ cells from 4 tadpoles) of bCNGA1Dend 2 fluorescence recovered in $20 \mathrm{~min}$ after photobleaching. A subpopulation of bCNGA1-Dend2 is mobile in the vertical direction, unlike rhodopsin, which is known to be confined in disks and is not expected to move vertically. Consistent with this expectation, rhodopsin-Dend2-1D4 fluorescence recovered by $<1 \%$ ( $n=15$ cells from 4 tadpoles). This minimal recovery of rhodopsin-Dend2-1D4 is likely due to experimental error, as the error range was $\pm 5 \%$ for lateral diffusion of rhodopsin. Alternatively, this minimal recovery may be caused by transition of green Dendra 2 from the triplet to the ground state, and would not represent actual movement of proteins. Thus, the recovery of bCNGA1-Dend2 was clearly more substantial than that of rhodopsin-Dend2-1D4, indicating that at least a fraction of bCNGA1-CNGA1 is slowly diffusing into the photobleached area. Despite this diffusion in the lateral OS PM, bCNGA1Dend 2 did not enter the membrane subdomains that are proximal to axoneme and the base of the OS. Such lack of diffusion must be explained by a diffusion barrier that separates the lateral OS PM from other PM regions at the base and proximal to axonemal microtubules. Thus our FRAP experiment suggests that OS $\mathrm{PM}$ is subdivided into at least two subdomains with and without CNGA1. confirmed by staining with fluorescently labeled phalloidin. After $24 \mathrm{~h}$ of cytochalasin D treatment, F-actin was fragmented in rod photoreceptors as evidenced by reduction in the number of integral filaments and an increase in the number of phalloidinpositive puncta (Fig. 6B, compare top left with bottom left). After prolonged exposure to cytochalasin D for $48 \mathrm{~h}$, F-actin was further disrupted (Fig. 6B, compare top right with bottom right).

To rule out any nonspecific effects of cytochalasin $\mathrm{D}$, we used a second, structurally unrelated F-actin disruptor, latrunculin A. Unlike cytochalasin D, which binds to and disrupts F-actin, latrunculin A binds to actin monomers and prevents actin from polymerizing (Coué et al., 1987; Spector et al., 1989). In retinas incubated with latrunculin A for $24 \mathrm{~h}$, the number and size of actin filaments were reduced (Fig. $6 B$, compare middle left with bottom left). Actin filaments were more disrupted with prolonged exposure to latrunculin A for $48 \mathrm{~h}$ (Fig. 6B, compare middle right with bottom right). In general, the effect of latrunculin A on F-actin was more pronounced and rapid than that of cytochalasin $\mathrm{D}$, as OSs demonstrated more severe destruction of $\mathrm{F}$-actin in latrunculin A than in cytochalasin D-treated retinas (Fig. 6B). As observed for cytochalasin D, latrunculin A inhibited the entrance of the bCNGA1-Dend 2 to the OS. Unlike cytochalasin D, however, latrunculin A did not cause aggregation of bCNGA1-Dend2 at the base of OSs in the majority of the cells (Fig. 6A, middle). This lack of aggregation is potentially due to a stronger effect of latrunculin A in disrupting F-actin, which would cause additional inhibition of CNGA1 trafficking. Overall, these experiments indicate that F-actin is essential for the PM trafficking of CNGA1.

\section{Continued trafficking of rhodopsin and altered trafficking of peripherin/rds contribute to the aberrant overgrowth of evaginations by F-actin disruption}

It was previously shown that cytochalasin $\mathrm{D}$ interferes with the morphogenesis of membrane in the OS causing overgrowth of the evaginations (Williams et al., 1988). Electron microscopic examination further confirmed the overgrowth of the disk evagi- 
A
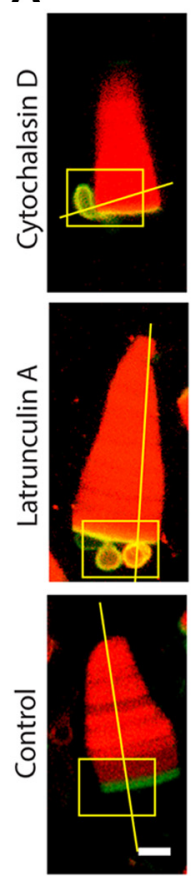

Rhodopsin-Dend2-1D4
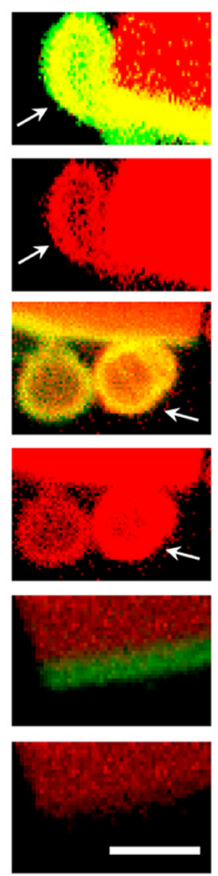
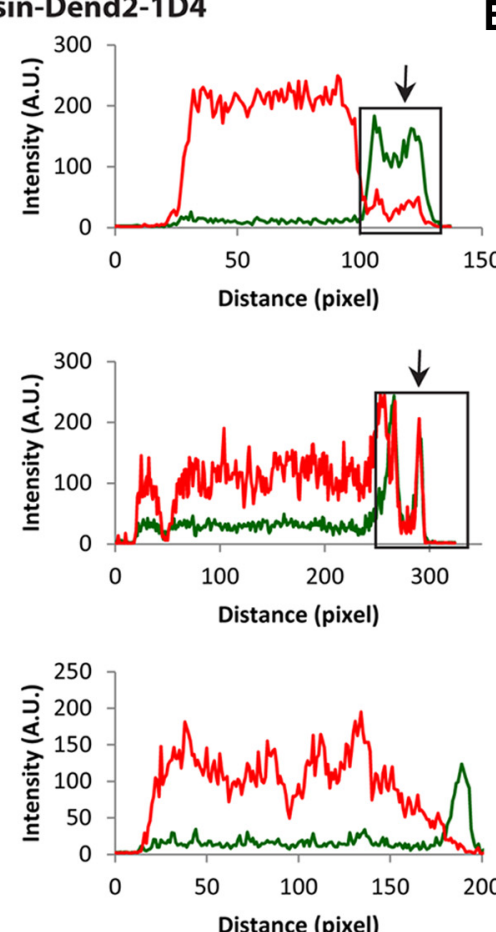

B
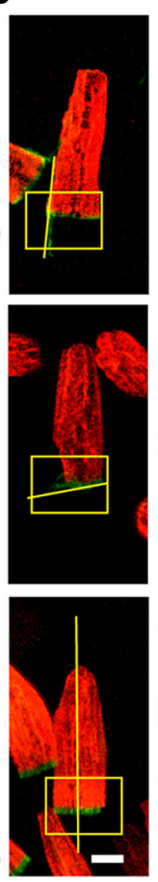

Peripherin/rds-Dend2
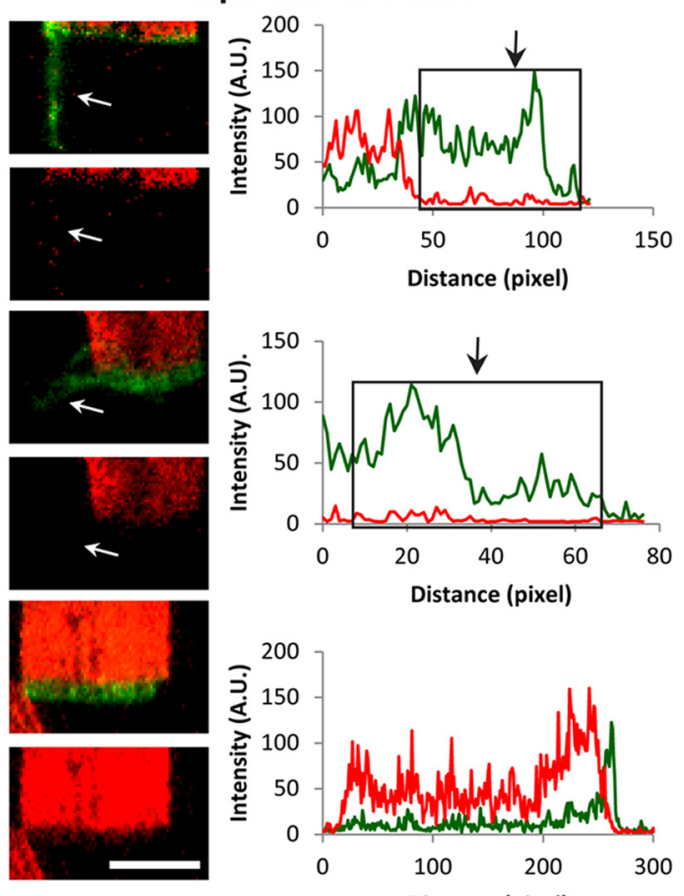
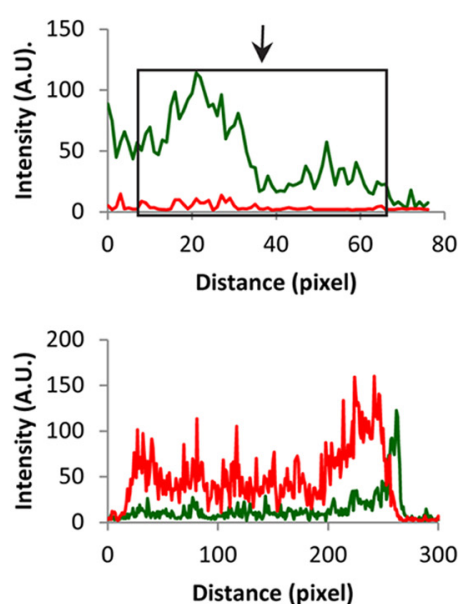

Figure 8. Evagination overgrowths induced by F-actin disruption contain rhodopsin and peripherin/rds. The photoconversion technique allows discrimination of old (red) from newly synthesized (green) proteins. Xenopus rods were imaged after cytochalasin D, latrunculin A, or DMSO control treatment for $24 \mathrm{~h}$. A, In cytochalasin D- and latrunculin A-treated rods, both old (red) and new (green) rhodopsin-Dend2-1D4 are observed in the evagination overgrowths (arrows). In control rods, evagination overgrowths are not observed, and new rhodopsin-Dend2-1D4 (green) is incorporated into new disks. $\boldsymbol{B}$, In cytochalasin D- and latrunculin A-treated rods, new peripherin/rds-Dend2 (green) is observed in the evagination overgrowths (arrows). 0 ld peripherin/rds-Dend2 (red) is not observed in these structures (arrows). In control rods, evagination overgrowths are not observed, and new peripherin/rds-Dend2 (green) is incorporated into new disks. Intensity profile charts $(\boldsymbol{A}, \boldsymbol{B}$, right) were drawn for old and newly added proteins along the lines on left images. Rectangles in the charts represent the areas of evagination overgrowths (arrows). Animals were $14 \mathrm{~d}$ old at the time of photoconversion. Images are from live and unfixed retinas. Scale bars: $5 \mu \mathrm{m}$. A.U., arbitrary units.

nations. Evaginations were extended alongside the OS or IS (Fig. $7 A$, left, arrow), and often formed membrane whorls (Fig. $7 A$, right, asterisks). In the absence of cytochalasin $\mathrm{D}$ treatment, evaginations did not overgrow (Fig. 7B). Lack of bCNGA1Dend2, a PM marker (Cook et al., 1989), in the area of overgrowth (Fig. $6 A$, top and middle) further suggests that the disk structures are evaginations, and not closed disks encased in an additional PM.

Previous autoradiography studies indicated that newly synthesized proteins are trafficked to the evagination in the presence of cytochalasin D (Williams et al., 1988), although the identities of the proteins were not known because of random radiolabeling. We focused specifically on the trafficking of rhodopsin and peripherin/rds as they are essential components of disk membranes. While previous studies focused on monitoring only newly synthesized proteins, we monitored both old and newly synthesized proteins. After photoconversion and with cytochalasin D or latrunculin A treatments, newly synthesized rhodopsin-Dend21D4 and peripherin/rds-Dend2 accumulated at the base of OS within overgrown structures (Fig. 8). Percentages of transgenic rods exhibiting evagination overgrowths after cytochalasin $\mathrm{D}$ and latrunculin A treatment were 68 and 78\%, and were also similar to the previously reported values (Williams et al., 1988). The absence of overgrowth in some of the cells is likely due to less active disk precursor synthesis in those cells, as a previous study demonstrated high cell to cell variation in synthesis activity (Besharse et al., 1977). While similar localizations were observed for newly synthesized proteins, remarkable differences were observed for the old (red) peripherin/rds-Dend 2 and rhodopsin-
Dend2-1D4, which existed before photoconversion. In the evagination overgrowth, we frequently observed old (red) rhodopsin-Dend2-1D4 (Fig. 8A, arrows); however, we did not observe old (red) peripherin/rds-Dend2 (Fig. $8 B$, arrows). These observations provide supporting evidence for the previously published ideas that rhodopsin is incorporated into evaginations, but peripherin/rds is not effectively incorporated into the evaginations under normal conditions (Williams et al., 1992) and hence before initiating cytochalasin D treatment. Existence of red rhodopsin-Dend2-1D4 indicates that the larger evaginations were grown from pre-existing and smaller evaginations.

\section{The evagination hypothesis is supported by the trafficking} patterns of the OS membrane proteins

Trafficking patterns of CNGA1, rhodopsin, and peripherin/rds are in line with the evagination hypothesis (Fig. 1, Hypothesis 2). According to the evagination hypothesis, disk membranes are sealed and isolated from the OS PM when the PM domain is formed simultaneously with the disk rim region. Such simultaneous formation is evidenced by enrichment of newly synthesized CNGA1 at the base of the lateral OS PM. The evagination hypothesis assumes that the bottom of the OS PM is a specific membrane domain where disk membrane precursors are synthesized (Fig. 1, Hypothesis 2). Consistent with this assumption, CNGA1 is prevented from entering this specific membrane domain likely due to the presence of a diffusion barrier. This prevention explains why CNGA1 cannot enter the disk membranes, even if the evaginations are apparently continuous with the rest of the OS PM where CNGA1 is localized. Observed effects of cy- 

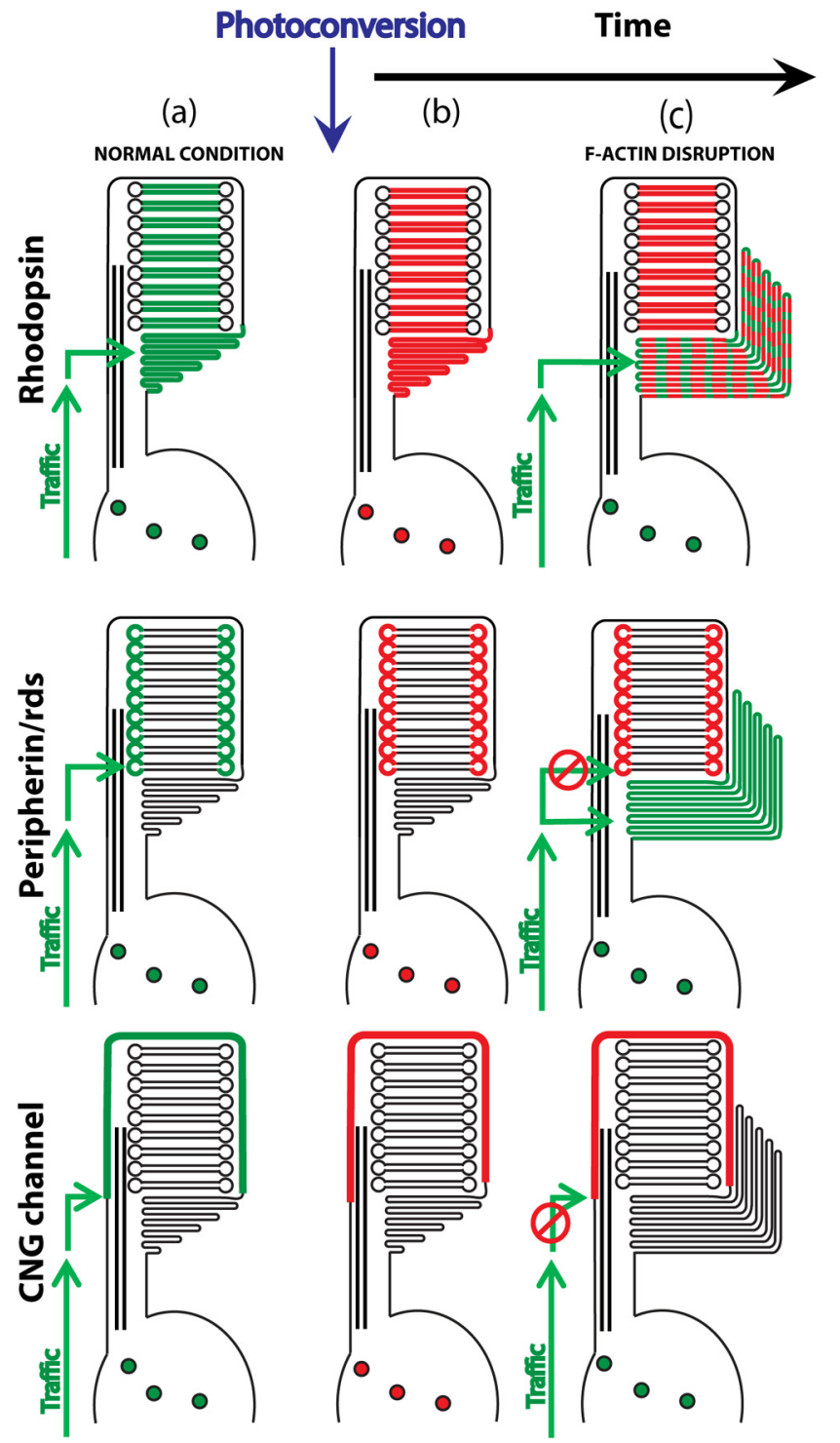

Figure 9. Differential targeting of rhodopsin, peripherin/rds, and CNG channel to the OS compartments. Schematic showing the summary of photoconversion experiments in this study. $\boldsymbol{a}$, Disk (rhodopsin), disk rim (peripherin/rds), and PM (CNG channel) protein trafficking in rod photoreceptor cell. According to the evagination hypothesis, rhodopsin is trafficked to evaginations, whereas peripherin/rds is not. CNG channels are incorporated into the OS PM as disk membranes are formed. Proteins are trafficked from the IS to the $0 S$. $\boldsymbol{b}$, Photoconversion turns Dend2 fusion proteins from green to red. This conversion is irreversible, and thus old proteins stay red. c, After F-actin disruption, rhodopsin-Dend2-1D4 and peripherin/rds-Dend2 are trafficked to the evagination overgrowths, while trafficking of the bCNGA1-Dend2 to the OS PM is inhibited. The presence of old and photoconverted rhodopsin-Dend2-1D4 in the evagination indicates that the evagination was the original destination of rhodopsin-Dend2-1D4 (compare $\boldsymbol{b}$ and $\boldsymbol{c}$ ). The lack of old and photoconverted peripherin/rds-Dend 2 in the evagination indicates that the evagination was not the original destination (compare $\boldsymbol{b}$ and $\boldsymbol{c}$ ).

tochalasin D and latrunculin A are consistent with defects in the disk rim sealing process, as evidenced by the failure of CNGA1 and peripherin/rds to enter OS PM and mature disks, respectively (Fig. 9). Peripherin/rds, which is usually trafficked to the mature disks (Arikawa et al., 1992), instead changed its destination to the disk evaginations after cytochalasin D and latrunculin A treatments. Under normal conditions, disk evaginations do not form rim regions that are characterized by hairpin-shaped curvature of membrane. In cytochalasin D-treated photoreceptors, however, a rim region is formed at the edge of overgrown evagination
(Williams et al., 1988), consistent with altered trafficking of peripherin/rds to the evaginations observed in this study. While old (red) peripherin/rds-Dend2 was not observed in the overgrown evagination, new (green) peripherin/rds-Dend 2 localized to the evaginations. These observations indicate that peripherin/rdsDend 2 started localizing to the evaginations as a consequence of F-actin deficiency (Fig. 9, middle row). While proper incorporation of CNGA1 and peripherin/rds requires F-actin, rhodopsin does not require these F-actins for its incorporation into the evaginations. The trafficking of rhodopsin is unaffected since evaginations are the normal destination (Fig. 9, top row; Nir and Papermaster, 1983). Therefore, in the absence of disk rim sealing in F-actin deficient rods, rhodopsin trafficking contributed to the overgrowth of the evaginations. Our observations are inconsistent with the endosome hypothesis (Fig. 1, Hypothesis 1) in which it is unclear how the disk rim is formed and coordination of rim and PM formation are unnecessary for the proper disk membrane formation. In the endosome hypothesis, continued trafficking of rhodopsin may lead to disk membrane overgrowth. However, formation of the open structures (Fig. 7A; Williams et al., 1988) would require the PM rupturing, which would totally destroy the OS (Fig. 2G). PM destruction usually causes necrosis of the cells (Golstein and Kroemer, 2007). We did not observe such destruction of OS structures or signs of necrosis during the formation of evagination overgrowths.

\section{Discussion}

A major goal of membrane biology is to understand how different membrane structures are formed, functionally specialized, and compartmentalized. Photoreceptor OSs serve as a suitable model to address these questions. The function of the OS PM is clearly specified by the terminal effector of phototransduction cascade, CNG channel, and the function of disk membranes is specified by the rest of phototransduction components. This study provides insight into how compartmentalization is maintained by unique coordination of morphogenic programs. It also explains why CNG channel is excluded from the disk membrane compartment, where CNG channel cannot function. CNG channel, a component of the OS PM, was preferably added to the base of the lateral OS PM; however, it was barely observed at the bottom of OS where disk membrane morphogenesis occurs. This unique trafficking pattern would prevent CNGA1 from being aberrantly incorporated into the disk membranes, whose morphogenesis occurs where CNGA1 is absent. When expressed in Xenopus rods, bCNGA1-Dend2 localized accurately to the OS PM regions that are proximal to the rim or incisures of disk membranes. This PM incorporation of bCNGA1-Dend2 was blocked by inhibitors of actin polymerization, cytochalasin $\mathrm{D}$ and latrunculin $\mathrm{A}$, which disrupt the cytoskeleton. These F-actin inhibitors did not alter the localization of pre-existing bCNGA1-Dend2, but specifically prohibited the entrance of newly synthesized bCNGA1-Dend 2 to the OS PM. Cytochalasin D, which induced an effect weaker than latrunculin A, did not completely block the entrance of bCNGA1-Dend 2 into the ciliary OS, and thus did not block the cilia targeting of the CNG channel. Actin cytoskeletal structure is observed around the site of disk membrane morphogenesis, and bridge the connecting cilium and the OS PM (Williams et al., 1992). This bridging region of actin filaments coincides with the area where trafficking deficiency was observed for bCNGA1Dend2. Therefore, our findings support a role of actin filaments in the subciliary PM targeting of the CNG channel.

The observed trafficking patterns for bCNGA1-Dend2 are supportive of the disk membrane evagination model, and are not 
supportive of the endosome model. In the evagination model, the closure of the evagination leads to disk rim formation, which is synchronized with de novo formation of the PM domain. This synchronization was evidenced by accumulation of newly synthesized bCNGA1-Dend2 to the basal OS PM. When actin filaments are disrupted, this synchronization was not observed. New bCNGA1-Dend2 cannot be incorporated to the PM, and the evaginations failed to close. In the current endosome model, synchronization of disk and PM formation is not assumed, and desynchronization of these two processes does not lead to failure of disk membrane closure. While the role of the CNG channel in the formation of nascent PM is unknown, the channel itself appears to play an important structural role in the OS. Disk membranes overgrow and misalign perpendicularly in mice lacking the products of the CNGB1 gene (Zhang et al., 2009). Based on cryoelectron microscopy tomography of these mice, disk membranes were found to protrude from the OS, suggesting poor integrity of the OS PM (Gilliam et al., 2012). While the individual roles of multiple splicing variants of CNGB1 gene remain to be clarified (Zhang et al., 2009), those observations support a structural role for the CNG channel and its associated proteins in the maintenance or morphogenesis of the OS.

In the originally proposed evagination model, disk rim and OS PM are formed simultaneously (Steinberg et al., 1980). Such synchronicity was abolished by disrupting F-actin, as observed in our study (Fig. 8). Peripherin/rds, which is usually trafficked to the rim as disks close, was trafficked to the evaginations after F-actin disruption. Peripherin/rds is a structural protein required for the integrity of the disk membrane structure. Trafficking of peripherin/rds to the evagination is consistent with the role of peripherin/rds in inducing membrane curvature (Wrigley et al., 2000; Kevany et al., 2013; Khattree et al., 2013). Overgrown evaginations, as observed by electron microscopy in this and previous studies (Williams et al., 1988), would require a larger edge with high membrane curvature, to which additional peripherin/rds can contribute. It was previously suggested that cytochalasin D inhibits initiation of new evaginations, but it does not affect the rate of membrane addition to the overgrowing evaginations (Hale et al., 1996). This previous assumption is consistent with continued trafficking of rhodopsin observed in this study, because rhodopsin is a major protein trafficked to evaginations, and it is cotransported together with lipid components of disk membranes (Rodriguez de Turco et al., 1997). Collectively, actin filaments are required for targeting of CNGA1 to the PM and targeting of peripherin/rds to the rim of maturing disks, but are not essential for targeting of rhodopsin to the evaginations (Fig. 9). The continuous uptake of rhodopsin and peripherin/rds would have contributed to the overgrowth of primordial disk membrane structures.

Once reaching the OS PM, the majority (68\%) of CNGA1 is rather immobile, and such immobility allowed us to discriminate newly synthesized CNGA1 from old and pre-existing CNGA1 in the OS PM. A subfraction (32\%) of CNGA was found mobile and diffusive. This diffusion of CNGA1 is slower than the lateral diffusion of rhodopsin; however, it is faster than rhodopsin's axial movements which are considered to be nonexistent. This presence of diffusion, albeit slow, should support the interpretation that a diffusion barrier exists to prevent the entrance of CNGA1 to the PM domain at the bottom of OS and proximal to axoneme. The slow movement and presence of immobile CNGA1 support the interpretation that CNG channels interact with other OS proteins, which restrict or inhibit the lateral diffusion of the channels. For example, peripherin/rds interacts with the CNG channel (Poetsch et al., 2001). Since peripherin/rds does not move between disk membranes (Tian et al., 2014), its interaction with CNG channels would tether them to single disk membranes and limit the longitudinal diffusion as observed with photoconversion and FRAP experiments. CNG channel also interacts with the $4.1 \mathrm{G}$ splice variant lacking the spectrin-actin binding domain (Cheng and Molday, 2013). The interaction is selective to CNG channels that are not bound to peripherin/rds. Therefore, such differential interactions may contribute to the formation of mobile and immobile fractions of CNGA1 observed in this study.

CNG channels are particularly enriched in the vertically oriented PM features proximal to incisures. Incisures are likely the sites of active synthesis and hydrolysis of cGMP, as guanylate cyclase (Karan et al., 2011) and phosphodiesterase (Muradov et al., 2010) are concentrated there. Theoretical study also predicts that incisures serve as a restricted volume in which the diffusion of cGMP is facilitated (Caruso et al., 2006), and hence CNG channels juxtaposed to incisures will be able to quickly respond to the changes in [cGMP]. The vertically oriented features will have impact on the calcium signaling as well. Since CNG channel conducts calcium ions and is known to interact with the $\mathrm{Na} / \mathrm{Ca}-\mathrm{K}$ exchanger (Molday and Molday, 1998; Schwarzer et al., 2000), local changes in $\left[\mathrm{Ca}^{2+}\right]$ would be possible around the vertical features by the combined action of CNG channels and the exchangers. The local changes in $\left[\mathrm{Ca}^{2+}\right]$ will be sensed by the GCAP family of calcium binding proteins (Gorczyca et al., 1994; Palczewski et al., 1994; Imanishi et al., 2002), which then will regulate guanylate cyclases enriched in incisures (Karan et al., 2011). Thus, vertical feature may allow the compartmentalization of cGMP and $\mathrm{Ca}^{2+}$ signaling in restricted volumes for effective and quick responses of the phototransduction cascade.

In summary, we have provided evidence for involvement of actin filaments in the subciliary trafficking of CNG channels using $X$. laevis rod photoreceptors, consistent with the evagination hypothesis. One potential candidate for linking actin and CNG channels is ankyrin G, which is suggested to play an important role in channel trafficking (Kizhatil et al., 2009). A more recent study, however, indicates the lack of interaction between CNG channel and ankyrin G (Cheng and Molday, 2013). While the evagination hypothesis has been predominant in the past two decades, another prominent hypothesis for disk membrane morphogenesis is the "endosome hypothesis" (Obata and Usukura, 1992; Chuang et al., 2007). However, the endosome hypothesis does not explain the incorporation of new components to the OS PM domain, and needs refinement. According to the endocytosis hypothesis, the evagination overgrowth should result in PM rupturing that must be detrimental to the rods. This hypothesis was from studies on mouse retina, in which evaginations are observed less frequently. Thus, it is an open question whether the difference in the appearance of the OS basal structures is dependent on species. Mouse is known to have unique basal OS organization. CPs, which are abundant in primate and frog rod photoreceptor, surround the area of disk membrane morphogenesis (Sahly et al., 2012). CPs are poorly formed in mouse, suggesting a different cell biological requirement of these structures between mouse and other species (Sahly et al., 2012). Regardless of the debates, however, it is clear that evagination hypothesis is valid for X. laevis rod photoreceptors, for which the evagination overgrowth would not occur if they did not exist in the first place. 


\section{References}

Arikawa K, Williams DS (1989) Organization of actin filaments and immunocolocalization of alpha-actinin in the connecting cilium of rat photoreceptors. J Comp Neurol 288:640-646. CrossRef Medline

Arikawa K, Molday LL, Molday RS, Williams DS (1992) Localization of peripherin/rds in the disk membranes of cone and rod photoreceptors: relationship to disk membrane morphogenesis and retinal degeneration. J Cell Biol 116:659-667. CrossRef Medline

Besharse JC, Hollyfield JG, Rayborn ME (1977) Turnover of rod photoreceptor outer segments. II. Membrane addition and loss in relationship to light. J Cell Biol 75:507-527. CrossRef Medline

Caruso G, Bisegna P, Shen L, Andreucci D, Hamm HE, DiBenedetto E (2006) Modeling the role of incisures in vertebrate phototransduction. Biophys J 91:1192-1212. CrossRef Medline

Chen TY, Peng YW, Dhallan RS, Ahamed B, Reed RR, Yau KW (1993) A new subunit of the cyclic nucleotide-gated cation channel in retinal rods. Nature 362:764-767. CrossRef Medline

Cheng CL, Molday RS (2013) Interaction of 4.1G and cGMP-gated channels in rod photoreceptor outer segments. J Cell Sci 126:5725-5734. CrossRef Medline

Chuang JZ, Zhao Y, Sung CH (2007) SARA-regulated vesicular targeting underlies formation of the light-sensing organelle in mammalian rods. Cell 130:535-547. CrossRef Medline

Chudakov DM, Lukyanov S, Lukyanov KA (2007) Using photoactivatable fluorescent protein Dendra2 to track protein movement. Biotechniques 42:553, 555, 557 passim. CrossRef Medline

Cook NJ, Molday LL, Reid D, Kaupp UB, Molday RS (1989) The cGMPgated channel of bovine rod photoreceptors is localized exclusively in the plasma membrane. J Biol Chem 264:6996-6999. Medline

Coué M, Brenner SL, Spector I, Korn ED (1987) Inhibition of actin polymerization by latrunculin A. FEBS Lett 213:316-318. CrossRef Medline

Gilliam JC, Chang JT, Sandoval IM, Zhang Y, Li T, Pittler SJ, Chiu W, Wensel TG (2012) Three-dimensional architecture of the rod sensory cilium and its disruption in retinal neurodegeneration. Cell 151:1029-1041. CrossRef Medline

Golstein P, Kroemer G (2007) Cell death by necrosis: towards a molecular definition. Trends Biochem Sci 32:37-43. CrossRef Medline

Gorczyca WA, Gray-Keller MP, Detwiler PB, Palczewski K (1994) Purification and physiological evaluation of a guanylate cyclase activating protein from retinal rods. Proc Natl Acad Sci U S A 91:4014-4018. CrossRef Medline

Gupta BD, Williams TP (1990) Lateral diffusion of visual pigments in toad (Bufo marinus) rods and in catfish (Ictalurus punctatus) cones. J Physiol 430:483-496. Medline

Gurskaya NG, Verkhusha VV, Shcheglov AS, Staroverov DB, Chepurnykh TV, Fradkov AF, Lukyanov S, Lukyanov KA (2006) Engineering of a monomeric green-to-red photoactivatable fluorescent protein induced by blue light. Nat Biotechnol 24:461-465. CrossRef Medline

Hale IL, Fisher SK, Matsumoto B (1996) The actin network in the ciliary stalk of photoreceptors functions in the generation of new outer segment discs. J Comp Neurol 376:128-142. CrossRef Medline

Imanishi Y, Li N, Sokal I, Sowa ME, Lichtarge O, Wensel TG, Saperstein DA, Baehr W, Palczewski K (2002) Characterization of retinal guanylate cyclase-activating protein 3 (GCAP3) from zebrafish to man. Eur J Neurosci 15:63-78. CrossRef Medline

Imanishi Y, Sun W, Maeda T, Maeda A, Palczewski K (2008) Retinyl ester homeostasis in the adipose differentiation-related protein-deficient retina. J Biol Chem 283:25091-25102. CrossRef Medline

Karan S, Tam BM, Moritz OL, Baehr W (2011) Targeting of mouse guanylate cyclase 1 (Gucy2e) to Xenopus laevis rod outer segments. Vision Res 51:2304-2311. CrossRef Medline

Kaupp UB, Niidome T, Tanabe T, Terada S, Bönigk W, Stühmer W, Cook NJ, Kangawa K, Matsuo H, Hirose T. (1989) Primary structure and functional expression from complementary DNA of the rod photoreceptor cyclic GMP-gated channel. Nature 342:762-766. CrossRef Medline

Kevany BM, Tsybovsky Y, Campuzano ID, Schnier PD, Engel A, Palczewski K (2013) Structural and Functional Analysis of the Native PeripherinROM1 Complex Isolated from Photoreceptor Cells. J Biol Chem 288: 36272-36284. CrossRef Medline

Khattree N, Ritter LM, Goldberg AF (2013) Membrane curvature generation by a C-terminal amphipathic helix in peripherin-2/rds, a tetraspanin required for photoreceptor sensory cilium morphogenesis. J Cell Sci 126: 4659-4670. CrossRef Medline

Kizhatil K, Baker SA, Arshavsky VY, Bennett V (2009) Ankyrin-G promotes cyclic nucleotide-gated channel transport to rod photoreceptor sensory cilia. Science 323:1614-1617. CrossRef Medline

Liebman PA, Entine G (1974) Lateral diffusion of visual pigment in photoreceptor disk membranes. Science 185:457-459. CrossRef Medline

Lodowski KH, Lee R, Ropelewski P, Nemet I, Tian G, Imanishi Y (2013) Signals governing the trafficking and mistrafficking of a ciliary GPCR, rhodopsin. J Neurosci 33:13621-13638. CrossRef Medline

Miyaguchi K, Hashimoto PH (1992) Evidence for the transport of opsin in the connecting cilium and basal rod outer segment in rat retina: rapidfreeze, deep-etch and horseradish peroxidase labelling studies. J Neurocytol 21:449-457. CrossRef Medline

Molday RS, Molday LL (1987) Differences in the protein composition of bovine retinal rod outer segment disk and plasma membranes isolated by a ricin-gold-dextran density perturbation method. J Cell Biol 105:25892601. CrossRef Medline

Molday RS, Molday LL (1998) Molecular properties of the cGMP-gated channel of rod photoreceptors. Vision Res 38:1315-1323. CrossRef Medline

Muradov H, Boyd KK, Haeri M, Kerov V, Knox BE, Artemyev NO (2009) Characterization of human cone phosphodiesterase- 6 ectopically expressed in Xenopus laevis rods. J Biol Chem 284:32662-32669. CrossRef Medline

Muradov H, Boyd KK, Artemyev NO (2010) Rod phosphodiesterase-6 PDE6A and PDE6B subunits are enzymatically equivalent. J Biol Chem 285:39828-39834. CrossRef Medline

Najafi M, Haeri M, Knox BE, Schiesser WE, Calvert PD (2012) Impact of signaling microcompartment geometry on GPCR dynamics in live retinal photoreceptors. J Gen Physiol 140:249-266. CrossRef Medline

Nieuwkoop PD, Faber J (1967) Normal table for Xenopus laevis (Daudin): a systematical and chronological survey of the development from the fertilized egg till the end of metamorphosis, p 282. Amsterdam: North-Holland.

Nir I, Papermaster DS (1983) Differential distribution of opsin in the plasma membrane of frog photoreceptors: an immunocytochemical study. Invest Ophthalmol Vis Sci 24:868-878. Medline

Obata S, Usukura J (1992) Morphogenesis of the photoreceptor outer segment during postnatal development in the mouse $(\mathrm{BALB} / \mathrm{c})$ retina. Cell Tissue Res 269:39-48. CrossRef Medline

Palczewski K, Subbaraya I, Gorczyca WA, Helekar BS, Ruiz CC, Ohguro H, Huang J, Zhao X, Crabb JW, Johnson RS (1994) Molecular cloning and characterization of retinal photoreceptor guanylyl cyclase-activating protein. Neuron 13:395-404. CrossRef Medline

Poetsch A, Molday LL, Molday RS (2001) The cGMP-gated channel and related glutamic acid-rich proteins interact with peripherin-2 at the rim region of rod photoreceptor disc membranes. J Biol Chem 276:48009_ 48016. Medline

Rodriguez de Turco EB, Deretic D, Bazan NG, Papermaster DS (1997) PostGolgi vesicles cotransport docosahexaenoyl-phospholipids and rhodopsin during frog photoreceptor membrane biogenesis. J Biol Chem 272: 10491-10497. CrossRef Medline

Roof DJ, Heuser JE (1982) Surfaces of rod photoreceptor disk membranes: integral membrane components. J Cell Biol 95:487-500. CrossRef Medline

Sahly I, Dufour E, Schietroma C, Michel V, Bahloul A, Perfettini I, Pepermans E, Estivalet A, Carette D, Aghaie A, Ebermann I, Lelli A, Iribarne M, Hardelin JP, Weil D, Sahel JA, El-Amraoui A, Petit C (2012) Localization of Usher 1 proteins to the photoreceptor calyceal processes, which are absent from mice. J Cell Biol 199:381-399. CrossRef Medline

Schwarzer A, Schauf H, Bauer PJ (2000) Binding of the cGMP-gated channel to the $\mathrm{Na} / \mathrm{Ca}-\mathrm{K}$ exchanger in rod photoreceptors. J Biol Chem 275: 13448-13454. CrossRef Medline

Sparrow DB, Latinkic B, Mohun TJ (2000) A simplified method of generating transgenic Xenopus. Nucleic Acids Res 28:E12. CrossRef Medline

Spector I, Shochet NR, Blasberger D, Kashman Y (1989) Latrunculinsnovel marine macrolides that disrupt microfilament organization and affect cell growth: I. Comparison with cytochalasin D. Cell Motil Cytoskeleton 13:127-144. CrossRef Medline

Steinberg RH, Fisher SK, Anderson DH (1980) Disc morphogenesis in vertebrate photoreceptors. J Comp Neurol 190:501-508. CrossRef Medline 
Tam BM, Moritz OL, Papermaster DS (2004) The C terminus of peripherin/ rds participates in rod outer segment targeting and alignment of disk incisures. Mol Biol Cell 15:2027-2037. CrossRef Medline

Tian G, Ropelewski P, Nemet I, Lee R, Lodowski KH, Imanishi Y (2014) An Unconventional Secretory Pathway Mediates the Cilia Targeting of Peripherin/rds. J Neurosci 34:992-1006. CrossRef Medline

Wang Q, Zhang X, Zhang L, He F, Zhang G, Jamrich M, Wensel TG (2008) Activation-dependent hindrance of photoreceptor $G$ protein diffusion by lipid microdomains. J Biol Chem 283:30015-30024. CrossRef Medline

Weitz D, Ficek N, Kremmer E, Bauer PJ, Kaupp UB (2002) Subunit stoichiometry of the CNG channel of rod photoreceptors. Neuron 36:881-889. CrossRef Medline

Wey CL, Cone RA, Edidin MA (1981) Lateral diffusion of rhodopsin in photoreceptor cells measured by fluorescence photobleaching and recovery. Biophys J 33:225-232. CrossRef Medline

Williams DS, Linberg KA, Vaughan DK, Fariss RN, Fisher SK (1988) Disruption of microfilament organization and deregulation of disk membrane morphogenesis by cytochalasin D in rod and cone photoreceptors. J Comp Neurol 272:161-176. CrossRef Medline
Williams DS, Hallett MA, Arikawa K (1992) Association of myosin with the connecting cilium of rod photoreceptors. J Cell Sci 103:183-190. Medline

Wright AF, Chakarova CF, Abd El-Aziz MM, Bhattacharya SS (2010) Photoreceptor degeneration: genetic and mechanistic dissection of a complex trait. Nat Rev Genet 11:273-284. CrossRef Medline

Wrigley JD, Ahmed T, Nevett CL, Findlay JB (2000) Peripherin/rds influences membrane vesicle morphology. Implications for retinopathies. J Biol Chem 275:13191-13194. CrossRef Medline

Young RW (1967) The renewal of photoreceptor cell outer segments. J Cell Biol 33:61-72. CrossRef Medline

Zhang Y, Molday LL, Molday RS, Sarfare SS, Woodruff ML, Fain GL, Kraft TW, Pittler SJ (2009) Knockout of GARPs and the beta-subunit of the rod cGMP-gated channel disrupts disk morphogenesis and rod outer segment structural integrity. J Cell Sci 122:1192-1200. CrossRef Medline

Zheng J, Trudeau MC, Zagotta WN (2002) Rod cyclic nucleotide-gated channels have a stoichiometry of three CNGA1 subunits and one CNGB1 subunit. Neuron 36:891-896. CrossRef Medline

Zhong H, Molday LL, Molday RS, Yau KW (2002) The heteromeric cyclic nucleotide-gated channel adopts a 3A:1B stoichiometry. Nature 420:193198. CrossRef Medline 